\title{
Conceptual Frameworks of Business Ethics
}

\author{
Andrey Galukhin \\ Department of History and Philosophy \\ Plekhanov Russian University of Economics \\ 117997, 36 Stremyanny Lane, Moscow, Russian Federation \\ E-mail: mystolbard@gmail.com
}

Elena Malakhova

Department of History and Philosophy

Plekhanov Russian University of Economics

Moscow, Russian Federation

E-mail: elena_malahova@bk.ru

\author{
Farid Gusejnov \\ Department of History and Philosophy \\ Plekhanov Russian University of Economics \\ Moscow, Russian Federation \\ E-mail:metafizika@mail.ru \\ Elena Novikova \\ Department of History and Philosophy \\ Plekhanov Russian University of Economics \\ Moscow, Russian Federation \\ E-mail: novikovaelena77@yandex.ru
}

\begin{abstract}
The following paper gives an account of the paradigmatic diversity of concepts and approaches applied in business ethics programs. Business ethics is introduced as a part of an interdisciplinary project of inquiry into the regulative foundations of business activity. Business ethics issues are classified with regard to interpersonal, organizational, and systemic contexts of business activity. Business ethics research programs are typically characterized by an a priori scale of moral reasoning, with the emphasis on criticism and complex approaches to moral problems that are independent of the problems of social responsibility. Due to the complexity of moral problems in business, there is a need for a special conceptual framework of ethical reflection and argumentation. The paper differentiates between the basic philosophical frameworks of moral reasoning that are typically applied in business, such as Utilitarianism, Deontology, and Virtue Ethics. These are evaluated in a comparative perspective. Different views on the ways of bringing ethics to business are introduced in terms of the distinction between two basic approaches - that of the moralists and of the institutionalists.
\end{abstract}

Keywords-business ethics; social responsibility; stakeholders; ethical framework; business relationships; morality; rationality; institutionalism

\section{INTRODUCTION}

Business ethics is a specific form of applied ethics. Business ethics examines a moral dimension of doing business and focuses on the ethical examination of business activities. As a discipline of applied ethics, it has theoretical foundations and a practical orientation. The methodological basis for business ethics research programs was provided by the integration of philosophical conceptions of moral reasoning and social theories into a complex project of interdisciplinary study of the regulative foundations of business activities, which was specified as the study of normative ethical frameworks of the relationships between people who work in business organizations, or participate in economic exchange.
The purpose of this paper is to produce a conceptual core of the extant definitions of the subject matter of business ethics and to provide a systemic account of philosophical frameworks of the moral reasoning that underlie alternative strategies of identifying and dealing with ethical issues in the sphere of business activities and relationships.

\section{Defining The SUBJECT MATter OF BUSINESS ETHICS AND THE SCOPE OF ITS PROBLEMS}

Business ethics is focused on the application of the strategies of moral reasoning to the activities of people engaged in business, and to the policies of economic organizations. As a discipline which assumes the relevance of ethical issues to business activities, business ethics involves a general study of moral standards as they apply or should apply to business institutions and to the relationships between the agents of business activity. Such a study is necessary for the elaboration and implementation of the practical programs of moral refinement of the relationships between the people who work within organizations, or have interests associated with business, or are otherwise affected by business dealings. In a practical sense, business ethics programs are oriented at improving the ethical climate in business on interpersonal, organizational, and systemic levels. The development of business ethics programs implies a critical consideration of business activity in terms of its social value, legal status, and conformity to moral standards embedded in the regulatory basis of the complex relationships between social actors engaged in economic exchange.

There is a demand for a synthesized conception of business ethics. When a business ethics program combines the principle of legal compliance with the principle of conformity with moral standards and fits this combination with the idea of social responsibility of business, this program can be introduced as a constitutive part of the whole project of the improvement of social environment in which businesses operate. Yet, some scholars argue that there is a clear distinction between business ethics as an academic 
discipline, on the one hand, and the building of relationships between business organizations and society in accordance with the conception of corporate social responsibility, on the other. For instance, Richard De George claims that business ethics deals with a set of intrinsically meaningful ethical issues and has a specific methodological profile which differentiates it from other disciplines. To justify this view, he points out, "1) the fact that business ethics sought to provide an explicit ethical framework within which to evaluate business, and especially corporate activities. Business ethics as an academic discipline had ethics as its basis. While social responsibility could be and was defined by corporations to cover whatever they did that they could present in a positive light as helping society, ethics had implicit in it standards that were independent of the wishes of corporations. To that extent, 2) the field was at least potentially critical of business practices - much more so than the social responsibility approach had been". [1. P.1]

Many business ethics research programs have emerged and various approaches have been differentiated with respect to the specific kind of moral problems that arise in the sphere of business activities and relationships. Within the scope of the most typical issues of business ethics are:

- Issues of workplace ethics. (The establishment of moral rights and obligations within the framework of employer-employee relationships, the issues of job discrimination, conflicts of interest, etc.);

- Issues of consumer ethics, as well as the issues of advertising ethics;

- Issues of marketplace ethics, pertaining to some moral aspects of competitive and anticompetitive behavior (specifically, the issues of Justice, Utility, and Rights);

- Issues of developing an ethical culture within corporations, or the issues of institutionalizing ethics within organizations and promoting ethical behavior;

- Issues of verifying corporate moral agency and of establishing social responsibility of business, as well as the issues of business contributions to the project of sustainable development.

All those complex ethical issues cannot be dealt with on the basis of moral reasoning which is restricted to the resources of 'common sense morality'. The most efficient way of developing a business ethics program lays through the integration of philosophical foundations of moral reasoning with practical recommendations on finding the proper solutions to ethical dilemmas and improving the ethical climate of business operations.

\section{PHILOSOPHICAL FRAMEWORKS OF MORAL REASONING IN BUSINESS}

The most influential ethical theories typically applied to the study of moral aspects of doing business are found in the traditions of Utilitarian Ethics, Deontology, Virtue Ethics, and other ethical frameworks. These theories constitute the core of alternative paradigms of ethical thinking and form a methodological basis for the rational discussion of ethical issues in business. Considerations of utility, or alternative considerations of rights and justice, as well as considerations of virtues and character, determine the rival strategies of moral reasoning and different patterns of ethical argumentation.

Utilitarianism is a consequentialist ethical theory, originally elaborated by J. Bentham and J. S. Mill. A central tenet of the Utilitarian Theory is that an act's rightness or wrongness is determined solely by the act's consequences. Utilitarianism can be specified as the view that actions and policies should be evaluated on the basis of the benefits and costs they produce for everyone in society. The Utilitarian principle holds that: 'An action is right from an ethical point of view, if and only if, the sum total of utilities produced by that act is greater than the sum total of utilities produced by any other act the agent could have performed in its place". [2. P. 78] So, Utilitarianism is a consequentialist ethical theory which advocates selection of that action or policy that maximizes utility.

Among the non-consequentialist theories, the most influential are the duty-based and rights-based theories that have been elaborated within the Deontological ethical framework. The Deontological approach was originally introduced by Immanuel Kant in his moral philosophy. Kant's ethics lays emphasis on duty and puts forward the principles of action instead of showing concern with consequences. The fundamental principle of ethics is explicated in a form of the categorical imperative: An action is morally right only if the maxim (or principle) represented by the action can be accepted as a universal law. This rule is binding on all rational beings. Kant gives another formulation of this basic moral principle: Always treat the humanity in a person as an end, and never merely as a means. Thus, Kant puts forward the respect for persons principle. As Norman E. Bowie explains, "Treating the humanity in a person as an end, and not as a means merely, in a business relationship requires two things. First, it requires that people in a business relationship not be used, i.e. they not be coerced or deceived. Second, it means that business organizations and business practices should be arranged so that they contribute to the development of human rational and moral capacities... These requirements, if implemented, would change the nature of business practice." [3. P. 8]

The Deontological framework provides an argumentative basis for the development of an ethically grounded theory of human rights. The idea that individuals possess certain moral rights which correlate with duties is implied by the respect forpersons principle which is the basic tenet of Deontological Ethics. Thus, the concept of moral right is central to the conceptual matrix of workplace ethics which is a significant subfield of business ethics. The proliferation of specific rights that have been claimed for employees in recent times indicates that there are many problematic aspects of the employer-employee relationship that derive from the area of legal regulation, and that are a matter of ethical concern. Claims made about moral rights of employees accord with a certain conception of the relationship between employer and employee. Thus, R. 
Dusca notes, that "the most recent and useful model of the employer-employee relationship in business ethics... is the stakeholder model...". [4. P. 262] Stakeholders are social actors - groups and individuals - that affect and are affected by the company's business operations. The stakeholder model of business relationships implies that "the business will impact on some of the interests of the stakeholders, be they members of the community where the business is located, potential hires, customers, other businesses with whom the company does business, stockholders or employees. If those interests are important, those stakeholder constituencies can make a rights' claim against the business". [4. P.262]

In addition to Utilitarian approaches and Deontological theories, there are other ethical frameworks that have proved to be relevant to the general subject of applying ethics to business. Among them, the most influential is Virtue Ethics. Virtue Ethics "focuses not so much on principles or the consequences of action, nor even the action itself, so much as on the agent, the person who performs the action, in the light of the circumstances and all of his or her other actions". [2. P. 30] An "agent-based" focus on what one ought to be, in contrast to an "action-based" focus on how one ought to act, "would look carefully at a person's moral character including whether a person's moral character exhibits virtue or vice". [2. P. 128] Such an approach would take the character traits of a person, namely their virtues and the vices, as the basic starting point for ethical reasoning. Robert Solomon insists on the prominent paradigmatic status of virtue ethics in business: "Business ethicists, understandably, are especially interested in what general traits allow the market, the free enterprise system, to work at full efficiency and which traits allow the market to work harmoniously in the midst of the larger society". [5. P. 33]

Conceptually divergent philosophical paradigms of moral reasoning are reflected by the alternative or even rival models of argumentation that are typically used in order to cope with ethically problematic situations in business. Though the basic ethical frameworks such as Utilitarianism, Deontology, and Virtue Ethics seem to offer alternative approaches and ways of solving moral problems. These theories should be methodologically specified with reference to a certain type and level of business activity. Thus, Deontological considerations, involving the concepts of moral rights and duties, may be quite compatible with the principles of Virtue Ethics if applied to the problematic situations that emerge on the interpersonal level of business activity. Likewise, a Utilitarian approach seems to be relevant to the systemic and organizational contexts, though it should be carefully balanced against the considerations of justice.

\section{MORALISM VS INSTITUTIONALISM}

Among the diversity of alternative views on the ways of bringing ethics to business, the most prominent are the views of 'moralists' and 'institutionalists', which correspond to the rival internalist and externalist conceptions of business ethics.
Moralists argue for the internalist account of morality. They stress the importance of motivational determination of individual and corporate behavior and pay particular attention to ethical decision making prompted by the propositional attitudes of an agent (a businessman). In the moralists' view, ethics can be brought to business through the internalization of moral norms and values by a rational agent. Moralists assume that properly internalized moral standards must be built into the structure of individual motivation for doing business. In their view, that is the most efficient and quite a natural way of imposing moral constraints on the rational behavior of a businessman.

Institutionalists approach the problem of providing a morally regulative basis for social interactions and economic behavior from the externalist point of view. Externalists consider business ethics to be a part of economic ethics and stress the importance of the institutional order of social relationships and economic activities. An adequate conception of business ethics should be elaborated within the framework of order ethics which focuses on the social order and the institutional environment in which individuals interact and pursue their economic interests. Institutionalists invoke the prisoners' dilemma and claim that "within the positive sum games of modern societies, the individual pursuit of advantages is, in principle, compatible with traditional ethical ideas like the solidarity of all". [6. P.13] Bringing ethics to business is a matter of incorporating morality in incentive-compatible rules and correlating systemic social order in an institutional environment of doing business. Within a carefully devised institutional system, the principles of social responsibility and compliance with moral standards will cohere to the principles of rational economic behavior.

\section{CONCLUSION}

Business ethics as an academic discipline has been developing through the proliferation of paradigmatic conceptions related to the divergent traditions in philosophical ethics, social theory, and schools of economics. Still, there is a need for a systemic approach that would identify ethical issues with reference to individual, institutional, and social dimensions of business activity.

Though some scholars tend to explain the initial development of business ethics programs in terms of the business communities' response to the urgent request for defining the social responsibility of business, it is clear that business ethics issues have intrinsic value and should be distinguished from the issues of social legitimatization of corporate business. Business ethics has developed into an academic discipline which is typically characterized by a priori scale of moral reasoning. The emphasis is on criticism and complex approaches to moral problems.

The practical implementation of business ethics programs involves changes in decision making processes on both individual and corporate levels. It has become a general requirement, which is consistent insofar it promises longterm business advantages, with a disposition to make rational choices, to act in accordance with the principles of 
distributive justice, to secure employees' moral rights, to take care of various stakeholders, and consider the consequences of business activities in terms of how they contribute to social welfare and how they conform with the goals of the sustainable development. These are the basic constituents of a strong ethical culture of doing business.

\section{REFERENCES}

[1] De George, R.T. 2008. A History Of Business Ethics. Markkula Center for Applied Ethics. Santa Clara University Press. https://www.scu.edu/ethics/focus-areas/business-ethics/resources/ahistory-of-business-ethics/ [accessed April 12, 2017].

[2] Velasquez, Manuel G., 2012, Business Ethics: Concepts and Cases. 7th ed. Pearson Education Limited, 496 p.

[3] Bowie, Norman E. 1999, A Kantian Approach to Business Ethics In: Frederick, Robert E. (ed.). A Companion to Business Ethics. Blackwell Publishers Ltd., 464 p.

[4] Dusca, R., 1999, Employee Rights. In: Frederick, Robert E. (ed.). A Companion to Business Ethics. Blackwell Publishers Ltd., 464 p.

[5] Solomon, Robert C., 1999b, Business Ethics and Virtue In: Frederick, Robert E. (ed.). A Companion to Business Ethics. Blackwell Publishers Ltd., 464 p.

[6] Lütge, Chistoph, 1999. Fundamentals of Order Ethics: Law, Business Ethics and the Financial Crisis. In: Bustamante Thomas and Onazi Oche (eds.), Global Harmony and the Rule of Law. Proceedings of the 24th World Congress of the International Association for Philosophy of Law and Social Philosophy, Beijing, 2009. Volume I. Pp. 11-21. 